\title{
SOBRE EL BINOMIO LIBERTAD-RESPONSABILIDAD RESPECTO \\ DE AQUELLOS QUE SE SOMETEN A LAS TÉCNICAS DE REPRODUCCIÓN MÉDICAMENTE ASISTIDAS: UN TEMA DE “DERECHO VIVIENTE” EN EL PERÚ
}

\author{
ABOUT THE BINOMIAL FREEDOM - RESPONSIBILITY OF THOSE \\ SUBMITED TO THE ASSISTED REPRODUCTIVE TECHNIQUES: A TOPIC \\ OF " LIVING RIGHTS "IN PERU
}

Juan Espinoza Espinoza ${ }^{1}$

\section{Resumen}

El autor expone en su artículo la problemática jurídica ocasionada por las técnicas de reproducción médicamente asistidas mediante el análisis de sentencias de casación de la Sala Civil permanente de la Corte Suprema de Justicia; realiza un análisis reflexivo y jurídico de la normatividad aplicable a los casos expuestos en las sentencias de casación materia de análisis, así como también muestra la insuficiencia de normatividad peruana para enfrentar este tipo de problemas.

\section{Palabras Clave}

Técnicas de reproducción medicamente asistidas, convenio de técnicas de reproducción médicamente asistidas, impugnación de maternidad.

\begin{abstract}
:
The author explains in his article the legal problems caused it by the assisted reproductive techniques, through the analysis of the jurisprudence of cassation from the Permanent Civil Chamber of the Supreme Court; it makes a legal and reflective analysis of the regulations applicable to the exposed cases in the jurisprudence analyzed, and it shows the lack of peruvian regulations to deal with such problems.
\end{abstract}

\section{Key words}

Medically assisted reproduction techniques, agreement of medically reproduction techniques, contestation of maternity.

Profesor de Derecho Civil en las Facultades de Derecho de la Universidad Nacional Mayor de San Marcos y de la Pontificia Universidad Católica del Perú. Miembro Correspondiente de la Academia de Derecho y Ciencias Sociales de Córdoba. 


\section{a) Primera parte: la impugnación de maternidad}

El Poder Judicial ya comenzó a enfrentar los problemas jurídicos de las técnicas de reproducción médicamente asistidas y lo ha hecho con un caso digno de una telenovela latinoamericana: "una ex conviviente infértil, quien luego de la ruptura sentimental y al tomar conocimiento del reciente compromiso conyugal de su ex pareja, resuelve someterse unilateralmente a la técnica de reproducción heteróloga (ovodonación), sin dudar para esto en utilizar los gametos germinales masculinos (espermatozoides) que mantenía crioconservados con anterioridad a la donación, en razón a que estos fueron obtenidos durante la época de la vigencia de su relación sentimental y a que fueron proporcionados voluntariamente para otra finalidad: realizar una prueba médica denominada espermatograma. Queda claro, en consecuencia, que nunca existió consentimiento para el tratamiento de reproducción asistida con gametos ajenos a la pareja"2. La ex conviviente, estando en cinta, demandó por alimentos al ex conviviente. Este realizó el reconocimiento voluntario de paternidad y demandó la impugnación de la maternidad por falsedad en el vínculo biológico y por contravenir el art. 7 de la Ley General de Salud. En un proceso aparte, la esposa del ex conviviente, en representación de su hijo, impugna la maternidad ex art. 399 del Código Civil, el cual, a la letra dice:

"El reconocimiento puede ser negado por el padre o por la madre que no interviene en él, por el propio hijo o por sus descendientes si hubiera muerto, y por quienes tengan interés legítimo, sin perjuicio de lo dispuesto en el artículo $395^{3 \prime \prime}$.

En esta línea de razonamiento, la esposa argumenta que su hijo (por ser hermano de la niña nacida) tiene "legítimo interés". Ella se ofrece a adoptar a la niña. Tanto la primera como la segunda instancia han declarado improcedente esta demanda. Sin embargo, la Sala Civil Permanente de la Corte Suprema de Justicia de la República, (Cas. No. 5003-2007-Lima), mediante Resolución de fecha 06.05.08, han pensado de manera distinta, atendiendo a que:

"Primero: La contravención de las normas que garantizan el derecho a un debido proceso se da cuando en el desarrollo del mismo, no se han respetado los derechos procesales de las partes, se han obviado

Como lo relata Alberto Gonzáles Cáceres, Maternidad a toda costa. Precisiones al especial de la primera casación en el Perú sobre reproducción asistida, en Diálogo con la Jurisprudencia, No. 123, Año 14, Gaceta Jurídica, diciembre 2008, 136.

El cual, por su parte, regla que: "El reconocimiento no admite modalidad y es irrevocable". 
o alterado actos de procedimiento, la tutela jurisdiccional no ha sido efectiva, el órgano jurisdiccional deja de motivar sus decisiones o lo hace en forma incoherente, en clara transgresión de la normatividad vigente y de los principios procesales. Segundo: De la demanda de fojas cuarenta se aprecia que la recurrente $\mathbf{M C O C H}$ actúa en representación de su menor hijo OFQO, e invocando los artículos 45 y 399 del Código Civil impugna el reconocimiento de maternidad efectuado por MAAD respecto de la menor ABAD, argumentando que la demandada no es la madre biológica de dicha menor, pues ella fue inseminada artificialmente con el óvulo de una mujer distinta y se utilizó los espermatozoides del esposo de la recurrente, COQC, sin el consentimiento de éste, mediante la técnica de reproducción asistida denominada "ovodonación", la que no está permitida en nuestro País conforme se colige de lo previsto en el artículo 7 de la Ley General de Salud. Tercero: Las instancias de mérito han declarado improcedente la demanda, fundamentando su decisión en que la parte demandante no ha acreditado interés económico o moral para ejercer la presente acción, al no demostrar que con el reconocimiento se haya afectado directa o indirectamente al hijo de la demandante, careciendo por ende de interés para obrar. Cuarto: El interés para obrar, de acuerdo a la doctrina mayormente aceptada sobre el tema, es la utilidad que para el titular de un derecho subjetivo emana de la tutela jurisdiccional, y según Hugo Rocco se determina realizando un: "juicio de utilidad, parangonando los efectos de la providencia jurisdiccional requerida con la utilidad que de tal providencia puede seguirse para quien la requiere, respecto de una determinada relación jurídica". Quinto: La legitimación procesal es la capacidad de ejercicio, en el proceso, de los derechos civiles; es la aptitud que tiene la persona de obrar directamente en un proceso como parte, defendiendo sus derechos. La legitimidad "ad causam" es la titularidad que tiene la persona respecto del derecho que demanda; es un elemento de procedencia de la pretensión jurídica demandada. En caso que la parte actora no tenga la legitimatio ad causam, la acción será, evidentemente, improcedente. Sexto: Existe interés para obrar procesalmente, cuando la parte actora invoca una utilidad directa, manifiesta y legítima, de índole material o moral, que lo lleve a proteger un derecho mediante el ejercicio de la acción. El juicio de utilidad debe referirse, en cada caso, a los efectos del acto jurisdiccional que se pide, o también en sentido inverso, el perjuicio o daño que pueda causar al actor, la falta del pronunciamiento requerido. En suma, el interés para obrar tiene contenido procesal al significar un presupuesto del derecho de acción y supone un estado 
de necesidad que se busca sea atendido por el Estado a través del órgano jurisdiccional. Séptimo: De acuerdo a ello, el menor hijo de la demandante, y en cuyo nombre actúa, OFQO, es hermano paterno de la menor, que la demandada ha reconocido como su hija, conforme al resultado del examen de ADN, según documento obrante a fojas diez, del que se colige que el padre de ambos menores es COQC, por lo que impugna dicho reconocimiento por las razones que expone, sosteniendo interés legítimo, pues este no concuerda con la realidad biológica, existiendo a ese efecto el parentesco consanguíneo. Octavo: Por lo tanto, no se trata de acreditar solamente la afectación al recurrente por el reconocimiento, sino el legítimo interés en el pronunciamiento, por su condición de hermanos del menor hijo de la demandante y la menor ABAD, en la necesidad de que el órgano jurisdiccional decida, respecto al reconocimiento efectuado por la demandada, que se señala transgrede lo dispuesto en el artículo 7 de la Ley General de Salud, y porque se vulnerarían derechos fundamentales de la citada menor, como su derecho a la propia identidad. Noveno: Por último, el interés legítimo a que se refiere el artículo 399 del Código Civil, está referido a una circunstancia de carácter personal, la parte es titular de un interés propio, distinto de cualquier otro, que proyectada al presente caso se encuentra dada por la condición de hermanos, lo que asegura el carácter personal, propio y legítimo del interés; además de ser único respecto a terceros que no se encuentran unidos por un vínculo de parentesco consanguíneo, con las consecuencias que determinan los artículos 475 del Código Civil y 93 del Código de los Niños y Adolescentes que regulan la prelación de los obligados a prestar alimentos, así como la obligación que existe a nivel de hermanos en la protección recíproca de sus intereses. Décimo: Estando además a lo dispuesto en el artículo VI del Título Preliminar del Código Civil, en cuanto al interés moral. 4.DECISION: a) Por las consideraciones expuestas, de conformidad con el dictamen fiscal, cuyos fundamentos se reproducen, y estando a lo establecido en el artículo 396 inciso $2^{\circ}$ ordinal 2.3 del Código Procesal Civil: Declararon FUNDADO el recurso de casación interpuesto por doña $\mathbf{M C O C H}$ en representación de su menor hijo OFQO; en consecuencia NULA la resolución de vista fojas ciento setenta y seis de fecha tres de agosto del dos mil siete; INSUBSISTENTE la apelada de fojas setenta y siete, su fecha veintitrés de octubre del dos mil seis. b) ORDENARON que el Juez de la causa expida nueva resolución estando a los considerandos precedentes. c) DISPUSIERON la publicación de la presente resolución en el Diario Oficial El Peruano, bajo responsabilidad" (el subrayado es mío). 
Esta decisión motiva las siguientes reflexiones:

a. Se están confundiendo categorías procesales (legitimidad para obrar) con categorías materiales (legítimo interés). La legitimidad procesal es la correspondencia entre la relación jurídica material con la procesal, mientras que el legítimo interés es una situación jurídica de ventaja inactiva que puede estar en relación con un derecho subjetivo. Lo que está en discusión no es el legítimo interés, sino la legitimidad para obrar activa del "hermano" ${ }^{4}$.

b. El art. 7 de la Ley General de Salud regula que, en el caso de las técnicas de reproducción técnicamente asistidas, la condición de madre genética y de madre gestante debe recaer en la misma persona... pero no regula que se debe hacer cuando no suceda ello: este es el problema. Acá nos encontramos frente a una mujer que es la madre gestante (pero no genética). Como lo hemos visto, si seguimos el modelo jurídico español, es madre la que da a luz . Como inteligentemente se ha observado, estamos "frente al típico caso de una madre soltera que decidió ejercer sus derechos reproductivos" $"$.

c. Hay discusión respecto de los alcances del art. 7, a propósito de la ovodonación. Un sector de la doctrina sostiene que este numeral de modo alguno prohíbe "la cesión de óvulos ni de espermatozoides" ${ }^{\prime}$, otro que "está proscrita (...) pues no existe identidad entre la madre genética y la madre gestante" ${ }^{\prime \prime}$ y no falta quien sostiene que "es un acto ilícito y constituye un abuso de derecho" ${ }^{\prime \prime}$. Me parece que la finalidad de esta prohibición debe circunscribirse a la denominada maternidad subrogada.

4 Se afirma que "para el ejercicio del derecho de acción no es necesario acreditar un determinado daño o afectación por causa del reconocimiento que se impugna.

En este sentido, en lo que respecta a la legitimidad e interés para obrar, no creemos que exista ningún obstáculo para que la madre en representación y velando por los derechos e interés de su menor hijo realice la impugnación del reconocimiento de la menor concebida mediante la procreación asistida" (Claudia Canales Torres, Madre ¿Hay una sola? A propósito del primer fallo de la Corte Suprema referente a la reproducción asistida, en Diálogo con la Jurisprudencia, No. 121, Año 14, Gaceta Jurídica, Lima, octubre 2008, 33). Aunque en el asunto de fondo la autora afirma que la impugnación no procede en atención a la "voluntad procreacional" de la madre (cit.).

5 Se afirma que éste puede ser considerado "como un principio general del Derecho" (Enrique Varsi Rospigliosi, Entrevista, La primera casación en materia de procreación asistida, Revista Jurídica del Perú, No. 93, Normas Legales, Lima, noviembre 2008, 16). El entrevistado argumenta adicionalmente el principio de afectividad, como principio inspirador del derecho de familia. Así "el afecto, el querer, el amor, la vocación que está implícita en las relaciones familiares, que es difícil normar pero que debe ser reinventado dentro de la procreación asistida" (cit., 17).

6 Mosquera Vásquez, Clara (2008) La genética en los tribunales peruanos. En: Diálogo con la Jurisprudencia, No. 121, Año 14, Gaceta Jurídica, Lima, octubre, p. 23.

Celinda Mosquera Vásquez, Clara. op. cit., 24.

8 Cieza Mora, Jario (2008) La técnica de reproducción humana asistida y la Corte Suprema ¿Quién entonces es la madre? En: Diálogo con la Jurisprudencia, N N 121, octubre, Edit. Gaceta Jurídica. cit., 27.

9 González Cáceres, Alberto (2008) Cuando mi madre es un número. Identidad genética e interés superior del niño, En: Revista Jurídica del Perú, cit., 46. 
Hay que superar la interpretación literal por una constitucional ¿acaso está prohibida la cesión de espermatozoides?. Prohibir la cesión de óvulos y no la de espermatozoides es evidentemente discriminatorio.

d. La parte demandante invoca el art. 399 del Código Civil, el cual prescribe que:

"El reconocimiento puede ser negado por el padre o por la madre que no interviene en él, por el propio hijo o por sus descendientes si hubiera muerto, y por quienes tengan interés legítimo, sin perjuicio de lo dispuesto en el artículo $395^{\circ \prime \prime}$.

Sin embargo este artículo debe interpretarse sistemáticamente con el art. 371 del Código Civil, que establece:

"La maternidad puede ser impugnada en los casos de parto supuesto o de suplantación del hijo".

En importante tener en cuenta la interpretación evolutiva-histórica: estos artículos han sido diseñados en caso de parto supuesto o suplantación de hijo, lo que resulta inaplicable -por su particular naturaleza- a los conflictos derivados de una maternidad surrogada.

e. Al impugnarse la maternidad, se está colisionando flagrantemente con el principio del mejor interés de la menor nacida bajo este tipo de técnica. Si se ampara la impugnación de la maternidad, se está condenando a la menor a ser arrancada de la familia monoparental de la cual forma parte, para ingresar a otro grupo familiar: con todos los transtornos que eso implica. Su identidad familiar está conformada con la madre que la gestó, dio a luz y que ahora la está criando. Por ello, concuerdo con quien sostiene que "en resguardo del derecho a la identidad de la menor no cabría la impugnación de reconocimiento de maternidad de la demandada"10.

f. Si lo que se quiere es proteger el derecho del menor a estar cerca de su hermana, éste tampoco debe colisionar con el de la niña a conservarse en su núcleo familiar. Una manera armónica es que exista un régimen de visitas para que ambos hermanos se relacionen y vivencien "su" lazo familiar. Esta sería la manera menos traumática de obrar.

10 Cieza Mora, Jairo. op. cit. 
g. Para colmo de males, los vocales (¿o "bocones"?) de la Corte Suprema han publicado los nombres completos de las partes en conflicto $y$, dado que se trata de un tema en el cual está en discusión un aspecto de la vida privada (impugnación de la maternidad), se ha debido guardar reserva de los nombres: se ha violado manifiestamente el derecho a la intimidad de las partes en conflicto. Por ello estoy totalmente de acuerdo con quien sostiene que "lo que nos preocupa es el hecho de que no se haya tenido cuidado en señalar con iniciales los nombres de los menores involucrados en el proceso, especialmente el de la menor cuyo origen biológico se discute, pues ello puede conllevar a que la menor A.B.A.D. tome conocimiento de su origen de un modo poco apropiado"11.

Para concluir este episodio, no hago más que suscribir este pensamiento: "un ser humano es una historia que incluye a sus genes pero no se reduce a éstos. La identidad es ser quien uno es, contemplando las particulares circunstancias que rodearon nuestro origen, no negándolas. Una niña concebida mediante una fecundación heteróloga no es huérfana, ni es hija de una donante anónima: su verdad personal es que tiene una madre que la deseó, gestó y dio a luz, pero de quien no heredará sus ojos, ni su facilidad para la aritmética; y cuando tenga edad para procesarlo adecuadamente, tiene derecho a saber que no es su hija en términos biológicos"12...sólo agregaría que también tiene derecho "a no saberlo": ésta será su decisión.

\section{b) La nulidad de la autorización de fertilización in vitro y transferencia embrionaria, así como del convenio de técnicas de reproducción asistida}

El señor COQC(quien es médico pediatra especializado en neonatología) interpuso otra demanda en contra de la señora MAAD (quien es obstetriz) y PRANOR, en la cual solicita la nulidad de la autorización de fertilización in vitro y transferencia embrionaria, así como del convenio de técnicas de reproducción asistida que él mismo suscribió. Con ello, queda acreditado que los hechos no son como se relatan en el proceso de impugnación de maternidad, ya que él dejó su material genético para someterse voluntariamente a técnicas de reproducción médicamente asistidas y no para un espermatograma. En la demanda, de fecha, 11.12.05, afirma que él firmó en blanco estos documentos y que él se sometía a este tipo de

\footnotetext{
Mosquera Vásquez, Clara. op. cit.

Siverino Bavio, Paula (2010) ¿Quién llamó a La cigüeña? Maternidad impugnada e identidad genética. Reflexiones a propósito de dos sentencias peruanas, En: Diálogo con la Jurisprudencia, No. 141, Año 15, Gaceta Jurídica, Lima junio, p.159.
} 
práctica, en el entendimiento que se iban a emplear sus gametos y los de la señora MAAD. Invoca, entre otros, el art. V del Título Preliminar del Código Civil (nulidad de los actos contrarios al orden público), art. IX del Título Preliminar de la Ley General de Salud (las normas de salud son de orden público), 7 de la Ley General de Salud (necesidad que madre gestante y madre genética recaigan en la misma persona) y 219.4 del Código Civil (nulidad por fin ilícito). En primera instancia, el Juez del 46 Juzgado Especializado en lo Civil de la Corte Superior de Justicia de Lima, mediante resolución No. 53, del 15.12.08, declaró infundada la demanda, en atención a que:

"del exhaustivo y riguroso análisis del documento denominado Convenio de Realización de Técnica de Reproducción Asistida obrante en autos, se tiene que, por la cláusula cuarta del referido documento los intervinientes solicitantes, admiten expresamente que la combinación del semen extraído y capacitado de EL ESPOSO, se combina con el óvulo donado, también previamente recogido en un plato de laboratorio donde se lleva a cabo la fecundación. Se consigna expresamente en dicha cláusula que los gametos a utilizar son provenientes de terceros, donados de manera anónima, y sin ánimo de lucro, que los usuarios consienten a no indagar acerca de la identidad de la donante, la que tampoco conocerá a la pareja usuaria; que, de la cláusula quinta del mismo documento se establece el consentimiento de la pareja a la realización de la FIV TE y finalmente de la cláusula octava del mismo documento, se señala que ambos declarantes reconocen haber leído el texto del acuerdo que suscriben, renunciando expresamente a cualquier acción civil, penal u otra que pudiere originarse en los hechos descritos en los párrafos anteriores, expresando realizarlo de buena fe, sin ánimo de lucro y que refleja la común intención que los anima y que convienen en forma irrevocable, suscribiendo dicho documento estampando el actor su firma y huella dactilar; que dicho acto, se encuentra ratificado con la autorización de Fertilización In Vitro y Transferencia Embrionaria efectuada en formato de la Clinica de Fertilidad y Ginecología Concebir, suscrita igualmente por ambos declarantes y de cuyo tenor se advierte que los intervinientes han tomado pleno conocimiento del procedimiento a utilizarse en la Técnica de Reproducción Asistida a la que en forma voluntaria se sometían y los riesgos del mismo, por lo que recogiendo el concepto de Devis Echanchía en cuanto a la clase de documentos, constituye un documento de actos dispositivos o constitutivos, es decir, actos de voluntad con el propósito de producir determinados actos jurídicos, consecuentemente, dicho acto jurídico conforme al contenido del documento analizado, cumple los requisitos de validez taxativamente señalados por el Art. 140 del Código Civil". 
La Sexta Sala Civil de la Corte Superior de Justicia, con resolución del 31.08.10, revocó la sentencia de primera instancia y declaró fundada la demanda, por cuanto:

"resulta evidente que los declarantes estaban autorizando la realización de un procedimiento contrario a una norma prohibitiva como el artículo 7 de la Ley General de Salud (...).

En consecuencia, el "Convenio de Realización de Técnicas de Reproducción Asistida" debe ser declarado nulo por violación del artículo V del Título Preliminar del Código Civil.

(...) En cuanto al acto jurídico denominado "Autorización de Fertilización In Vitro y Transferencia Embrionaria" debe relevarse que, igualmente, contiene una autorización para que en el procedimiento de reproducción asistida puedan utilizarse gametos provenientes de terceros o del Banco de Gametos, los que luego de ser fecundados serían transferidos al útero de la mujer.

Por consiguiente, también este acto jurídico trasgrede una norma de orden público como resulta ser el artículo 7 de la Ley General de Salud".

Sin embargo, esta sentencia cuenta con un voto discordante, en el que se sostiene que la demanda debe ser declarada improcedente, porque:

"se debe tener como premisa que la nulidad del acto jurídico importa que el acto jurídico carece de fuerza vinculante como mecanismo autorregulador de intereses privados, dejándose constancia que la sentencia que así lo declara no tiene carácter constitutivo, sino que es meramente declarativo puesto que, la verificación de la ausencia de un requisito de validez constituye una causa originaria, congénita, orgánica, consustancial al acto e importa que el acto carezca de efectos y por tanto se produce ipso iure, sin necesidad incluso de su impugnación, siendo que para que la nulidad opere como causal de ineficacia no tiene necesidad de ser declarada judicialmente, siendo que las partes se pueden comportar como si el evento nunca hubiese tenido lugar. Sin embargo, no se puede desconocer que el acto jurídico nulo puede ser fuente de efectos, aun de aquellos negociales, en la medida que las partes, si bien no vinculadas, han ejecutado prestaciones. ..

(...) Para el caso que nos ocupa tenemos que el actor pretende la declaración de nulidad de 1. Autorización de Fertilización In Vitro y Transferencia embrionaria del 05 de Agosto de 2004 y 2. Convenio de Técnicas de Reproducción Asistida, sin embargo, cabe precisar que la relación 
jurídica obligacional generada como consecuencia de dicho acuerdo se ha agotado en todo su iter contractual y ha producido los efectos jurídicos esperados por las partes al haber dado lugar a la procreación de una menor (el subrayado es mío).

(...) Por consiguiente, la nulidad de los actos cuestionados no presenta efecto jurídico que pueda ser privado y/o suspendido, asimismo, es imposible volver a su estado anterior y pretender desaparecer los derechos y obligaciones que hubieran nacido y/o la restitución de los bienes que se hubieran entregado, siendo que por la naturaleza del acuerdo la realización de la prestación pactada ha modificado la realidad de forma irreversible, advirtiéndose además que la pretendida nulidad, no puede afectar la eficacia de un acto realizado, la cual involucra en interés de una tercera persona.

(...) En este orden de ideas, tenemos que nuestro ordenamiento adjetivo, en el inciso 6) del artículo $427^{\circ}$ del Código Procesal Civil señala que el Juez declarará improcedente la demanda, cuando el petitorio fuese jurídica o físicamente imposible, por lo que, estando a lo expuesto se evidencia que existe imposibilidad física y jurídica para decretar la nulidad de los actos jurídicos que se demandan, puesto que no es posible eliminar, retrotraer ni modificar los efectos generados como consecuencia de dichos actos, por lo que la demanda incurre en causal de improcedencia, dejándose constancia que el actor tiene expedito su derecho de reclamar la indebida conducta que atribuye a las demandadas en la vía de acción [judicial o administrativa] en un proceso autónomo para tal fin".

Estas decisiones motivan las siguientes reflexiones:

a. Se confunde el concepto de imperatividad con el de orden público. El orden público es un conjunto de principios de diversa naturaleza (económicos, sociales, jurídicos, éticos, entre otros) que constituyen el pilar fundamental de la estructura y funcionamiento de la sociedad. En efecto, el concepto de norma imperativa debe ser identificado con el de norma insustituible por la voluntad de los particulares, mas no debe ser, necesariamente, asimilado al concepto de orden público. El carácter de ineludibilidad (o de insustituibilidad) de una norma no coincide, forzosamente, con la idea de orden público ${ }^{13}$. Por ejemplo, el art. 1328

13 Loris, Lonardo (1993) Ordine pubblico e illiceità del contratto, ESI, Napoli, p. 137. El autor propone que toda estructura normativa impone un propio y definido orden que deriva de la organización de un cierto modelo ético, político, institucional y económico (en una palabra: social) por medio de reglas previamente dispuestas y que, además, es necesario tomar conciencia del hecho de que, si los fundamentales criterios reguladores se obtienen principalmente del conjunto de valores normativos, el orden público no puede considerarse agotado en su genérica previsión (op. cit., 337). 
del Código Civil contiene una norma imperativa que expresa que todas las estipulaciones sobre exoneración y limitación de la responsabilidad por dolo o culpa inexcusable del deudor o de los terceros de quien este se valga son nulas. Dentro del ámbito de la categoría de las normas imperativas se distinguen, las normas prohibitivas, las cuales establecen un impedimento y las preceptivas, que establecen un mandato. Pueden absolver tanto intereses privados como intereses públicos ${ }^{14}$. El art. 242, numeral 2 del Código Civil, contiene una norma de orden público en la cual se establece que no pueden contraer matrimonio entre sí los consanguíneos en línea colateral dentro del segundo y tercer grados. Sin embargo, se prescribe que, en el caso del tercer grado, el juez puede dispensar este impedimento cuando existan motivos graves. En esta última disposición, como puede verse, está ausente el carácter de ineludibilidad o inevitabilidad.

b. De una interpretación sistemática del art. IX del Título Preliminar y 7 de la Ley General de Salud (las normas de salud son de orden público), se entiende que la prescripción que madre gestante y madre genética recaigan en la misma persona tiene el carácter de orden público y no de imperatividad. No se olvide que no toda contravención a una norma de orden público implica, necesariamente, la nulidad (art. 219, numeral 8 del Código Civil).

c. El demandante (que es médico) afirma haber sido inducido al error, cuando los documentos que firmó decían claramente que los gametos pueden ser de terceros. Es por ello que invocó el binomio libertadresponsabilidad: si uno tiene una pareja, es libre de someterse a este tipo de prácticas y, en caso de una ruptura, tiene el derecho de ordenar que ya no se utilice su material genético. De no hacerlo, surge la responsabilidad de ser padre de la criatura que nazca bajo este procedimiento.

d. Aún en el escenario (no compartido) que se entienda que el art. 7 de la Ley General de Salud es imperativo, se produjo un acto nulo, cuyos efectos precarios ya se produjeron y son irreversibles: la niña producto de este acto jurídico nació y fue reconocida por el propio señor Quispe.

e. Justamente por ello, soy del criterio que la sentencia que declara judicialmente la nulidad tiene naturaleza constitutiva (y no declarativa).

14 Di Bona, Laura, De Cicco, M. Cristina, Ferroni, Lanfranco y Aquila Vilella (1998) Le nullità negoziali di diritto comune, speciali e virtuali, a cura de Lanfranco Ferroni, Giuffrè, Milano, p. 135. 
La decisión de la mayoría de la segunda instancia ha declarado una (inútil y) simbólica nulidad.

Por suerte, ante el recurso de casación interpuesto, la Sala Civil Permanente de la Corte Superior de la República, con Cas. No. 4323-2010-Lima, del 11.08.11, declaró nula la sentencia de segunda instancia, confirmando la de primera, en atención a que:

"SÉTIMO.- Que, debemos observar que la inseminación artificial permite la posibilidad de la maternidad subrogada o vientre en alquiler, lo cual no es nuestro caso y que además no se encuentra reconocida legalmente en nuestro país, sin embargo, los hechos acaecidos tienen sustento en la técnica de reproducción asistida, denominada ovodonación en virtud de la cual la mujer puede gestar, pero es incapaz de ovular, por lo que se requiere de una donante para que le ceda el óvulo necesitado, al respecto se debe señalar que si bien dicho procedimiento no se encuentra legislado, sin embargo en virtud del axioma jurídico de que "todo lo que no está prohibido está permitido", reconocido por el Tribunal Constitucional: "En el ámbito del derecho constitucional opera el apotegma jurídico que dice que 'solo le está permitido al Estado aquello que expresamente le ha sido conferido' ello a diferencia de lo dispuesto para la ciudadanía, la que se rige por el principio de que 'aquello que no está prohibido, está permitido'"', por consiguiente el aludido procedimiento de "ovodonación" no es ilícito ni constituye delito, constituyendo más bien un vacío normativo y jurisprudencial.

OCTAVO.- Que, habiendo quedado establecido que el proceso de fecundación cuestionado no deviene ilegal, corresponde verificar si los actos jurídicos contenidos en los documentos denominados Autorización de Fertilización In Vitro y Transferencia embrionaria, y Convenio de realización de Técnica de Reproducción Asistida, se encuentran inmersos en causal de nulidad, en ese sentido se aprecia de la cláusula cuarta del segundo documento que los intervinientes (demandante y demandada) admiten expresamente: "Que tal fecundación se realizará mediante la técnica de reproducción asistida denominada FIV TE, la cual consiste en que el semen extraído y capacitado de EL ESPOSO, se combina con el óvulo donado, también previamente recogido en un plato de laboratorio donde se lleva a cabo la fecundación. Los gametos a utilizar son provenientes de terceros donados de manera anónima, y sin ánimo de lucro. (...)" y en la cláusula octava declaran haber leído el documento que suscriben, lo cual configura una manifestación de voluntad válida y además ratificada en el documento denominado autorización de Fertilización In Vitro y Transferencia Embrionaria; no debe dejar de mencionarse que como consecuencia del proceso de fecundación se produjo el nacimiento de una niña, quien resulta protegida en virtud de lo dispuesto en el artículo 1 del 
Código Civil, artículo 4 de la Convención Americana sobre Derechos Humanos, y artículos 2, 3, 6 y 12 de la Convención sobre los derechos del niño, que regulan los principios rectores sobre el interés superior del niño; en tal sentido se cumplen con los requisitos previstos en el artículo 140 del Código Civil. Por consiguiente, lo resuelto por la Sala Superior no se ajusta a derecho, correspondiendo declarar fundado el recurso de casación, casar la sentencia de vista y en sede de instancia confirmar la sentencia apelada".

Sin embargo, se cuenta con un incomprensible voto discordante del vocal Walde Jáuregui, en el que se sostiene que:

"al no esgrimirse los motivos que llevaron a determinar que la técnica FIV TE Modalidad de Ovodonación resulta ser un acto contrario al ordenamiento jurídico, al no existir una justificación adecuada de la decisión adoptada, en tanto, se requiere verificar las motivaciones que llevaron a la Sala Superior establecer que los hechos que sirven de base a la decisión se encuentran contenidos en el supuesto normativo contenido en la norma conforme a los parámetros interpretativos citados en el considerado que precede-lo que resulta ser de ineludible exigencia para una correcta justificación de la decisión adoptada-, es pertinente ordenarse la emisión de un nuevo fallo, máxime si un pronunciamiento como el emitido transgrede los principios del debido proceso y la motivación de las resoluciones judiciales; por lo que en ejercicio de la facultad nulificante del juzgador prescrita en el artículo 176 del Código Procesal Civil, corresponde anular la resolución de vista a efectos de que la Sala Superior emita nuevo pronunciamiento teniendo en cuenta las consideraciones de la presente resolución".

Resulta lamentable la actitud de ciertos magistrados que, pudiendo actuar en sede de instancia, no lo hacen, sustrayéndose de su deber de administrar justicia.

\section{c) ¿El parto siempre determina la maternidad?}

Al parecer, no. Este es el caso que nos obliga a replantear las excepciones a este principio: una mujer casada, si bien puede producir óvulos sanos, está impedida de gestar por cuanto padece de una insuficiencia renal e hipertensión arterial y ello pondría en serio riesgo su vida. La madre de ella decide surrogarse y asume la gravidez del embrión formado por su hija y el esposo de ésta. Al momento del parto, la clínica deja constancia en el "certificado de nacido vivo" que la "madre" es la abuela y ello es inscrito en la partida de nacimiento. En este caso no hay discusión de maternidades: madre e hija están de acuerdo que la niña nacida es de la pareja de los esposos 
y que quien "la gestó" es la abuela. A efectos que se rectifique la partida de nacimiento, la hija interpone una demanda de impugnación de maternidad en contra de la madre. El Décimo Quinto Juzgado Especializado en Familia, con Resolución No. 31, del 06.01.09, como no podía ser de otra manera, la declaró fundada, en atención a que:

"Según el Diccionario Jurídico de Guillermo Cabanellas, "madre es la mujer que ha dado a luz uno o más hijos", y en tal sentido, según el Derecho Romano "mater semper certa est etiam si vulgo concepterit", es decir "la maternidad será siempre cierta con el solo ver a una mujer gestante y después, con el infante en brazos", concepto que con el avance de la ciencia y con las técnicas de reproducción asistida (TERAS) tendientes a suplir los factores de infertilidad de las personas, ha dejado de ser ciertas en su totalidad, y dicho concepto tradicional con el devenir del tiempo y el avance de la ciencia y tecnología, específicamente la llamada "reprogenética" ha quedado obsoleto; tal es así que el derecho contemporáneo (Derecho Genético) crea nuevos conceptos de maternidad y por ende representa un problema jurídico con diferentes matices, cuya solución y regulación legal resulta insoslayable para armonizar las relaciones humanas en sociedad; (...).

Que habiéndose determinado objetiva y científicamente, que la demandante (...) tiene la calidad de "madre biológica" lo que la doctrina y la ciencia también califica como "madre genética" de la citada niña, y doña (...) como "madre sustituta", queda determinar jurídicamente cual de las dos es considerada como "madre de la menor", aquella que aportó sus óvulos y por ende sus genes para la fecundación de la niña o aquella que albergó en su vientre durante toda la etapa de gestación y alimentó a la niña hasta su nacimiento; Que al respecto la "Ley General de Salud", Ley No. 26842 determina en su Artículo $7^{\circ}$ "Toda persona tiene derecho a recurrir al tratamiento de su infertilidad, así como a procrear mediante el uso de técnicas de reproducción asistida, siempre que la condición de "madre genética" y de "madre gestante" recaigan sobre la misma persona"...; A que sin embargo, ¿cómo se determina la filiación si las condiciones de "madre genética" y "madre gestante" recaigan sobre diferentes personas?, situación fáctica que no está prohibida legalmente, pero tampoco está expresamente permitida, y a tenor de lo dispuesto en el Artículo 2 inciso 24 letra a) de la Constitución Política del Estado, que regula el Principio de Reserva, en virtud del cual: "Nadie está obligado a hacer lo que la ley no manda, ni impedido de hacer lo que ella no prohíbe"; y por consiguiente considerándose lícita tal conducta, sólo nos queda determinar si es amparable la pretensión demandada, considerando que la conducta de (la abuela) se ha realizado sin fines de lucro, en forma altruista y por amor a su hija (...), como 
lo afirma en su Declaración de Parte de fojas 414. Que regresando al concepto tradicional, salvo los casos de adopción, "madre sólo hay una" la misma que se determina por la "filiación biológica", por la identidad sanguínea, por la identidad biológica, que los genes transmiten de padres a hijos, la herencia de los caracteres anatómicos, citológicos y funcionales entre los padres y los hijos; y por lo tanto debe ampararse la pretensión demandada, pese a que en el acta de nacimiento de la niña se encuentra registrada y expresamente reconocida como madre a (la abuela) y lleva yuxtapuesto a su nombre y luego del primer apellido del padre, el primer apellido de ésta; dejándose de aplicar los dispuesto en el Artículo 395 del Código Civilis" (el subrayado es mío).

Evidentemente, no se podía fallar de otra manera: lo contrario generaría que la abuela se convierta en madre, la madre en hermana y el padre...jen progenitor junto con la suegra! Sin embargo, es pertinente hacer las siguientes consideraciones:

a. Se asume la posición que el art. 7 de la Ley General de Salud no es una norma imperativa, ya que -en puridad- no hay ninguna sanción frente a su incumplimiento.

b. Se entiende que cabe la maternidad subrogada si se trata de un acto altruista: con lo cual estamos dentro de los alcances del art. 6 del Código Civil.

c. El parto no siempre determina la maternidad; pero tampoco ésta va (necesariamente) identificada con la carga genética. Hay que analizar las particularidades de cada caso. Prueba de ello es que en el caso de la señora MAAD sí es determinante el parto y en este caso no. Un elemento a tenerse en cuenta es la denominada "voluntad procreacional", sin dejar de lado el mejor interés del menor.

Por ello, coincido con que "los conceptos de "maternidad" y "paternidad" deben ser deconstruidos y construidos, ya no bajo la luz de categorías normativas del siglo diecinueve, sino en atención a las nuevas y plurales formas de establecer lazos afectivos en las sociedades modernas, lo que incluye variados modelos de organización familiar y formas diferentes, más complejas, de determinación de la filiación, en una ampliada esfera de libertad para construir relaciones familiares. En este esquema resulta vital para establecer la filiación, en el caso de la fecundación heteróloga, la

15 El cual establece que "El reconocimiento no admite modalidad y es irrevocable". 
presencia de la voluntad procreacional y social: es decir, preguntarse quién decide buscar y asumir la maternidad"16.

Sin embargo, en esta sentencia adicionalmente se advierte que quedan crioconservados en la clínica tres embriones y se ordena que en el plazo de dos años, la pareja haga "efectivo su derecho a la vida" implantándolos a la demandante o mediante surrogación sin fines de lucro. Si bien, "obligar a una mujer enferma a gestar por sí o bien buscar quién geste por ella, a tres óvulos fecundados, y poner a tal fin un plazo perentorio de dos años, bajo amenaza de iniciarle a ella y su esposo un proceso por abandono de menores es ir demasiado lejos"17, creo que es importante reflexionar en atención al derecho a la vida de estos concebidos extracorpóreos y cederlos a quienes efectivamente tengan "voluntad procreacional".

\section{d) Sobre la insuficiencia del instrumental legislativo nacional para enfrentar este tipo de problemas}

Para entender este caso es preciso determinar la relación familiar entre todas las partes en conflicto: la señora $\mathbf{P}$ (casada con el señor $\mathbf{S}$ ) tiene un sobrino mayor de edad, el señor $\mathbf{P}^{\mathbf{1}}$ (que convive con la señora $\mathbf{C}$ ). Al no poder tener hijos, la tía contrata con su sobrino y su conviviente, para que esta última sea sometida a una técnica de reproducción médicamente asistida con el material genético del señor S. Producto de ello nace una niña, inscrita en el RENIEC como hija del señor $\mathbf{P}^{1}$ y su conviviente, siendo sin embargo, hija biológica del señor $\mathbf{S}$. La niña, desde días de nacida, vive con la pareja S-P. Para regularizar su situación jurídica, la pareja, S-P acude al Primer Juzgado Transitorio de Familia Tutelar de la Corte Superior de Lima, para pedir la adopción por excepción de la niña.

En efecto, el art. 128 del Código de los Niños y Adolescentes, Ley No. 27337, del 02.08.00, regula que:

"En vía de excepción, podrán iniciar acción judicial de adopción ante el Juez especializado, inclusive sin que medie declaración de estado de abandono del niño o del adolescente, los peticionarios siguientes:

a) El que posea vínculo matrimonial con el padre o madre del niño o el adolescente por adoptar. En este caso el niño o adolescente mantienen los vínculos de filiación con el padre o madre biológicos; 
b) El que posea vínculo de parentesco hasta el cuarto grado de consanguinidado segundo de afinidad con el niño o adolescente pasible de adopción; y

c) El que ha prohijado o convivido con el niño o el adolescente por adoptar, durante un período no menor de dos años" (el subrayado es mío) .

Entonces, al ser la señora $\mathbf{P}$ “tía abuela” de la niña, pide la adopción por excepción conjuntamente con el padre biológico. Al parecer, el señor $\mathbf{P}^{1}$ y su conviviente, no obstante haber entregado a la menor, posteriormente solicitaron que les sea devuelta. Con sentencia del 15.04.10, se declara fundada la demanda de adopción, atendiendo a un análisis de la salud física y psíquica de los preadoptantes, así como su solvencia moral y de lo actuado en la audiencia única. Sin embargo, se deja "claramente establecido que de modo alguno se ha tomado en cuenta el acuerdo entre las partes conocido como "madre subrogada" y que se ha cuidado que "el interés superior del niño sea la consideración principal". El señor $\mathbf{P}^{1}$ y la conviviente apela esta decisión.

La Segunda Sala Especializada de Familia de Lima, de la Corte Superior de Justicia de Lima, con resolución No. 25, del 30.11.10, confirmó la sentencia de primera instancia. En dicha resolución se informa de la denuncia penal que tienen el señor $\mathbf{P}^{1}$ y su conviviente, por cuanto la señora $\mathbf{C}$ (cuando estaba embarazada) amenazaba con abortar, a efectos que se le entreguen sumas de dinero. En esta sentencia se invoca la doctrina de la protección integral y (también) el interés superior del menor. Los demandados interpusieron recurso de casación.

La Sala Civil Permanente de la Corte Suprema de Justicia de la República con sentencia del 06.12.11 (Cas. No. 563-2011 Lima) declaró infundado el recurso de casación.

Como se advirtió, este caso demuestra palmariamente la insuficiencia de los modelos legislativos nacionales para resolver los problemas que se pueden presentar en un caso de maternidad subrogada. En efecto, se debe tener en cuenta que:

a. En este caso, no estaba en discusión la validez de este contrato (que, a la luz del art. V del Título Preliminar del Código Civil, es nulo); pero sí la maternidad de la niña. 
b. La señora $\mathbf{P}$ era biológicamente tía abuela de la menor; pero desde 9 días de nacida, aquella asumió el rol social y familiar de madre. La señora $\mathbf{C}$ -qué duda cabe- es la progenitora.

c. La demanda no era por nulidad de contrato, sino por adopción por excepción. Entonces no estaba en discusión quién era la madre: se partía de la premisa que la madre era la señora $\mathbf{C}$.

d. Resulta interesante constatar que el principio del mejor interés del menor debe imperar tanto en la adopción por excepción como en el caso de una impugnación de maternidad en el caso de técnicas de reproducción médicamente asistidas (que no está contemplado en nuestro código civil). En efecto, el art. 371 del Código Civil, sería inaplicable en este tipo de supuestos.

e. Si bien el resultado, en el proceso de la adopción por excepción, fue el que respondía a una efectiva tutela del interés del menor, al no contar con modelos jurídicos idóneos, se ha llegado al absurdo que el padre biológico sea el adoptante de su propia hija.

f. Téngase en cuenta que hay una orientación jurisprudencial que está inaplicando los arts. $396^{18}$ y 404 del Código Civil ${ }^{19}$, que precluían la posibilidad que un hijo matrimonial, cuya paternidad no haya sido contestada, pueda ser reconocido o demandado extrajudicialmente la filiación extramatrimonial. En efecto, la Sala Civil Transitoria de la Corte Suprema de Justicia de la República con sentencia del 17.07.13 (Cas. No. 2726-2012 del Santa), declaró:

"Que, en tal sentido, se verifica que la menor de iniciales M.L.G.C., y el demandante N.H.R.M, vienen desarrollando un tratamiento de padre e hija, incluso hacen vida familiar con la madre biológica, así fluye del expediente acompañado sobre anulabilidad y reconocimiento de paternidad de menor, conforme a la declaración asimilada de E.E.C a folios diez, en la cual manifiesta que desde abril de dos mil tres, se encuentra conviviendo con N.H.R.M en compañía de la menor de iniciales M.L.G.C., versión que no ha sido desvirtuada por el demandado, asimismo obra a folios ciento noventa y seis del expediente principal el informe psicológico practicado

18 El cual prescribe que: “El hijo de mujer casada no puede ser reconocido sino después de que el marido lo hubiese negado y obtenido sentencia favorable".

19 Que regula: "Si la madre estaba casada en la época de la concepción, sólo puede admitirse la acción en caso que el marido hubiera contestado su paternidad y obtenido sentencia favorable". 
a la menor en cuyos resultados se señala que la niña se identifica con su familia, incluye dentro de la dinámica al padre que vive con ella, a la figura paterna lo refleja como protector y cariñoso, todo lo cual determina el estado constante de familia de la niña con el demandante, lo que afirma su filiación, siendo ello así, resulta procedente declarar inaplicable, para el presente caso y sin afectar su vigencia, lo previsto en los artículos 396 y 404 del Código Civil, de conformidad con el derecho a la identidad consagrado en el artículo 2 inciso 1 de la Constitución Política del Estado, ello se justifica acorde al principio del interés superior del niño y adolescente, en la afirmación de la identidad filiatoria concordante con su realidad familiar y biológica de la menor de iniciales M.L.G.C., en esas circunstancias la justicia mediante el control difuso posibilita que la realidad filiatoria y vivencia familiar encuentre su legitimación legal".

El fundamento jurídico de la inaplicación es, al igual del caso que estamos discutiendo, a propósito del padre biológico, el derecho a la identidad del menor y el principio del interés superior del niño.

g. Por ello, frente a un conflicto de maternidades deben tenerse presentes los siguientes principios:

i) El parto determina la maternidad.

ii) La maternidad genética, que tiene como correlato, el derecho a la identidad del menor.

iii) El interés superior del menor.

iv) La voluntad procreacional.

Por ejemplo, en el caso de la señora MAAD prima el principio de que el parto determina la maternidad y la voluntad procreacional; en el caso de la señora si resulta inaplicable el principio de que el parto determina la maternidad y predomina el criterio de la maternidad genética y en el caso de la señora $\mathbf{P}$ no se aplica el principio de que el parto predomina la maternidad, ni el de la maternidad genética y predomina la voluntad procreacional (con el dato particular que su esposo es el padre biológico y, por tanto, hay una tutela adicional al derecho a la identidad del menor). Principio inspirador de todos debe ser el del interés superior del menor. 


\section{REFERENCIAS}

Canales Torres, Claudia (2008) Madre ¿Hay una sola? A propósito del primer fallo de la Corte Suprema referente a la reproducción asistida. En : Diálogo con la Jurisprudencia, No. 121, Año 14, Gaceta Jurídica, Lima, octubre, p. 33

Cieza Mora, Jario. (2008) La técnica de reproducción humana asistida y la Corte Suprema ¿Quién entonces es la madre? En: Diálogo con la Jurisprudencia, N 121, Año 14, Edit. Gaceta Jurídica. octubre, p. 27

Di Bona, Laura; De Cicco, M. Cristina; Ferroni, Lanfranco y Aquila Vilella (1998) Le nullità negoziali di diritto comune, speciali e virtuali, a cura de Lanfranco Ferroni, Giuffrè, Milano, p. 135.

Gonzáles Cáceres, Alberto (2008) Maternidad a toda costa. Precisiones al especial de la primera casación en el Perú sobre reproducción asistida. En: Diálogo con la Jurisprudencia, No. 123, Año 14, Gaceta Jurídica, diciembre, p.136.

González Cáceres, Alberto (2008) Cuando mi madre es un número. Identidad genética e interés superior del niño, En: Revista Jurídica del Perú, $\mathrm{N}^{\circ}$ 93, noviembre, Edit. Normas Legales, Lima. cit., 46.

Loris, Lonardo (1993) Ordine pubblico e illiceità del contratto, ESI, Napoli, p. 137.

Mosquera Vásquez, Clara (2008) La genética en los tribunales peruanos. En: Diálogo con la Jurisprudencia, No. 121, Año 14, Gaceta Jurídica, Lima, octubre, p. 23.

Siverino Bavio, Paula (2010) ¿Quién llamó a La cigüeña? Maternidad impugnada e identidad genética. Reflexiones a propósito de dos sentencias peruanas. En: Diálogo con la Jurisprudencia, No. 141, Año 15, Gaceta Jurídica, Lima junio, p.159.

Fecha de recepción : 20 de julio de 2015

Fecha de aceptación : 28 de agosto de 2015 